\title{
Correction to: Icariside II promotes the differentiation of human amniotic mesenchymal stem cells into dopaminergic neuron-like cells
}

\author{
Wei Kuang ${ }^{1} \cdot$ Tao Liu $^{1} \cdot$ Fang $\mathrm{He}^{2} \cdot{\text { Limei } \mathrm{Yu}^{2} \cdot \text { Qian Wang }}^{1} \cdot{\text { Changyin } \mathrm{Yu}^{1}}^{1}$ \\ Published online: 28 April 2021 \\ (C) The Society for In Vitro Biology 2021
}

\section{Correction to: In Vitro Cell.Dev.Biol.-Animal} https://doi.org/10.1007/s11626-021-00556-8

The last word of the title of this article ("cells") was missing in the article as originally published.

The original article has been corrected.

The online version of the original article can be found at https://doi.org/ 10.1007/s11626-021-00556-8

\section{Changyin $\mathrm{Yu}$}

ycynerve@163.com

1 Department of Neurology, The Affiliated Hospital of Zunyi Medical University, Zunyi, Guizhou, China

2 Key Laboratory of Cell Engineering in Guizhou Province, The Affiliated Hospital of Zunyi Medical University, Zunyi, Guizhou, China 